\title{
Health Care with Indigenous Women: Respectful Partnerships
}

\author{
Joanne Whitty Rogers ${ }^{1}$, Marion Alex ${ }^{2}$ and Cathy MacDonald ${ }^{3}$ \\ St. Francis Xavier University, Rankin School of Nursing. Antigonish, Nova Scotia, \\ Canada \\ ${ }^{1}$ jrogers@stfx.ca, ${ }^{2}$ malex@stfx.ca, ${ }^{3}$ cmacdon@stfx.ca
}

\begin{abstract}
World cultures are comprised of two forms - individualist and collectivist. The dominant form of culture in western Europe and North America is the individualist form. However, most of the world's cultures, including Indigenous cultures, are collectivist, where loyalty to community and relationality outweighs individualism. In a shared world, we need dialogue between and among cultures if we are to achieve harmony and understanding. The health state of Canada's Indigenous people is considerably lower than that of non-Indigenous Canadians. Health inequities are associated with low income and a lack of accessible and culturally safe health care. A complex web of socioeconomic, cultural, historical, and political factors affects health. Partnerships grounded in respect in working with Indigenous communities can begin to address health inequities. A Two-Eyed Seeing approach serves as a guide to respectful partnerships by bringing people with different ways of knowing together. Using illustrative stories and findings from our respective practice and research in Mi'kmaw and Inuit communities, and informed by the Truth and Reconciliation Committee of Canada report, this paper is a philosophical discussion of the importance of respectful and trustworthy relationships between Indigenous and non-Indigenous people.
\end{abstract}

Keywords: Indigenous, Mi'kmaq women, Two-eyed seeing, nurses, Partnerships, Research, Practice

\section{Introduction}

"Reconciliation must support Aboriginal people as they heal from the destructive legacies of colonialization that have wreaked such havoc in their lives. But it must do even more. Reconciliation must inspire Aboriginal and non-Aboriginal peoples to transform Canadian society so that our children and grandchildren can live together in dignity, peace, and prosperity on these lands we now share". It's from the Truth and Reconciliation Commission of Canada [1].

Population health inequities exist between Indigenous and non-Indigenous Canadians; epidemiological statistics demonstrate major discrepancies among Aboriginal Canadians compared to the general Canadian population and these are not showing significant signs of improvement. Life expectancy is shorter; infant mortality is higher; suicide, addictions, and injuries are more prevalent; and incidences of chronic illnesses such as diabetes and

Article history:

Received (July 18, 2019), Review Result (September 22, 2019), Accepted (November 6, 2019) 
respiratory illnesses are higher [1]. Heart disease is 1.5 times higher in First Nations communities than in the general population. Type II diabetes is 3 to 5 times higher in First Nations versus non-Indigenous Communities [2]. Moreover, the incidence of diabetes was "more than 4 times higher among First Nations women than among non-First Nations women and more than 2.5 times higher among First Nations men than among non-First Nations men. According to the Health Inequities and Social Determinants of Aboriginal Peoples Health [3][4][5] poor health status is often associated with the Social Determinants of Health $(\mathrm{SDOH})$ including low income, less education, lack of accessible health services and lack of culturally competent/sensitive health care, all of which contribute to health inequities. NonIndigenous people must reconsider our relationships with what Indigenous peoples have considered the sacred space between humans and the land [6] the air, soil, water, animals, and plants upon which we all depend for health [7]. Raising awareness and implementing effective policies to address maternal/newborn and reproductive health care, diabetes, and other chronic health conditions - not to mention policies to protect the land's shared air, soil, and water can improve health outcomes. Therefore, we believe that there is an urgency for non-Indigenous health professionals to work alongside Indigenous people in conducting respectful research and providing competent health care that helps Indigenous people develop interventions to address their health problems using a partnership approach.

Aboriginal is an inclusive term that refers to First Nations, Inuit, and Métis people according to the Canadian Constitution (Government of Canada, 2019). Indigenous peoples "is a collective name for the original peoples of North America and their descendants. Often, 'Aboriginal peoples' is also used". The terms Aboriginal and Indigenous will be used interchangeably according to how they are used by the authors that are being referenced in this paper[8].

In this descriptive paper, the authors will focus on Indigenous women's health as it relates to clinical practice and research concerning the TRC recommendations. This paper will include clinical practice and research examples that demonstrate the value of partnerships among non-Indigenous nurses and Indigenous women. We discuss briefly historical accounts of contributing factors, including trust and distrust, sharing world views using the 'Two-Eyed Seeing' approach and the 4 R's using respect, relevance, reciprocity, and responsibility in conducting research partnerships [9]. This paper is also informed by the articulation of the concept of accompaniment as a new model for 'aid work' that is grounded in authentic partnership between western health professionals and marginalized people [10]. The concept of accompaniment has resulted in significant and positive developments linking health and human rights in some of the poorest regions of the world [10]. In addition, examples from our clinical and research endeavors convey the spirit of partnership and readiness to move forward in working together.

Indigenous women who give birth within the medical model of maternity care, which is so prevalent throughout the western world, world face profound philosophical and practical challenges that affect maternal/child/family health. The World Health Organization (WHO) recently highlighted the prevalence of mistreatment of pregnant and birthing women in general by healthcare providers and/or systems worldwide has been highlighted recently [11]. Specifically, Indigenous people experience higher rates of racism and discrimination than the general population [12]. A typology of such mistreatment within seven themes: physical abuse, sexual abuse, stigma and discrimination, failure to meet professional standards of care, the poor rapport between women and providers, and healthcare conditions and restraints were presented [13]. Sometimes termed 'obstetrical violence' [14][15], parallels can be drawn between the mistreatment of women in pregnancy and childbirth and violence against women 
in general [16]. Gender-based violence in all its forms has disturbing health effects. Violence or disrespect shown to pregnant and birthing Indigenous women occurs during a most spiritually and corporeally vulnerable time of their lives.

In Canada, significant concerns related to disrespectful maternity care are expressed by Aboriginal women [17][18][19]. In the Canadian arctic, Inuit women are coerced to give birth alone in faraway hospitals, traveling in winter's harsh storms and 24/7 darkness, because western medicine and politics deem that to be 'safer' than birthing in their home community. Conceptualizations of 'risk' can be western-medical or Indigenous, however, they are not necessarily the same thing. Women from racially and culturally marginalized groups commonly report cultural insensitivity to them in childbirth, both within policy and within individual patient-provider interactions [20][21].

In a participatory action qualitative study, the authors reported that mainstream healthcare systems are poorly aligned to address the healthcare needs of Aboriginal people because mainstream systems tend to conceptualize health and illness as stemming from 'lifestyle' or cultural differences; often overlooking the contextual factors that shape health and illness [22]. Aboriginal women are resilient, and many are addressing their health "by taking action to address some of the determinants of health, even though they were confronted with considerable disadvantages and adversity" [22]. Some women communicated that they were "taking care of their health by becoming educated, being employed, and instituting early childhood learning". Aboriginal women demonstrate resilience and strength despite serious health disparities.

Aboriginal women often describe clinical and research encounters that are associated with discrimination and disrespectful discourses and actions by non-Aboriginal providers, leaving the women feeling dehumanized and their health concerns downplayed or dismissed[23][24][25][26]. It is within this context that the abuses of power must be acknowledged. It is respectfully and ethically appropriate to ask what works for Aboriginal people, what are their priorities, what was their past like, and what they hope for now in the present and future from the perspective of their life context. The Canadian Nurses Association Code of Ethics guides ethical relationships and making decisions in conjunction with the nurses' professional standards of care, best practices, research, and other regulations that guide nursing practice, and calls for nurses to provide culturally safe care [27]. The National Aboriginal Council of Midwives recognizes the importance of traditional healing practices and increases the number of Indigenous professionals working in health care [28].

While much remains unclear, the everyday health realities of Aboriginal women and families in relationships with western health, education, and social welfare systems are profoundly complex and call for evidence-informed research. The TRC calls "upon those who can effect change within the Canadian health care system to recognize the value of Aboriginal healing practices and use them in the treatment of Aboriginal patients in collaboration with Aboriginal healers and Elders". Doing so calls for better understanding and stronger authentic non-hierarchical partnerships among non-Aboriginal health researchers and health care providers with Aboriginal communities. The authors hear the frustrations of well-intentioned nurses, doctors, teachers, social workers, and others who see their efforts of trying to remedy the problems encountered by Aboriginal people as often being unsuccessful and lamentable given the volume of aid and 'welfare' extended. How do we shift such hierarchical thinking from knowing what is best for Aboriginal women and families to working in authentic partnerships? To provide culturally safe and appropriate health care, non-Aboriginal health care providers need to learn more about what Aboriginal people consider to be relevant, appropriate, and healing. 
Despite extensive research in health care and the relative availability of educated healthcare providers, Aboriginal people continue to experience discrimination, disrespect, and marginalization in healthcare settings across Canada [29][30][31][32]. Victim blaming is highly prevalent. Sensitivity to the reality of discrimination, the disempowerment inherent in pity or victim-blaming, and other injustices embedded in life experiences can provide a beginning point for a healthcare system that is culturally safe and humane. Aboriginal people and non-Aboriginal health care providers must work together towards the repair, and restoration of relationships and partnerships. The TRC calls upon medical and nursing schools in Canada to require all students to take a course dealing with Aboriginal health issues, including the history and legacy of residential schools, the United Nations Declaration on the Rights of Indigenous peoples, treaties and rights, and Indigenous teachings and practices. This will require skill-based training in intercultural competency, conflict resolution, human rights, and anti-racism

As non-Aboriginal health professionals do not have answers and perhaps do not even know what the questions are; the call for partnerships in research and practice is imperative. "Research conducted from the vantage point of patients is critical to improving the provision of services" in health care [30]. Committing to fostering health equity in the form of partnerships with Indigenous peoples is also critical. Sometimes it is Aboriginal people themselves who identify their issues and want to engage in research with non-Aboriginal people [32]. In the spirit of TRC, this is a time for reclaiming culture, languages, and world views. The authors remind us that "Relationships with the land - and thus with each other have been severed"[33]. It is time that Aboriginal people are re-presented to healthcare professionals, as strong independent people with strengths and self-determination. Research that pays attention to relational care and the well-being of people can serve as a vehicle for change.

\section{Aboriginal people in Canada: historical accounts}

Colonialism changed the landscape and culture of the Americas in many ways, as settlers integrated, rapidly outnumbering the Indigenous populations. Encounters between European settlers and Aboriginal people were marked by the exploitation of the Aboriginal population [34]. Racial discrimination resulted in entire nations, such as the Beothuks of Newfoundland, being eliminated [35]. "Historical trauma" that Aboriginal people have experienced is like post-traumatic stress disorder (PTSD), if not more complex because factors such as language, culture, and land rights need to be considered [36]. An "extremely toxic and deadly past has served to insidiously dislocate and disconnect individuals, families, and communities". The trauma of Residential Schools and the injustice of relocating people to leftover plots of land called reserves has "relegated generations of Indigenous people to the margins of maldevelopment". "The residential school system was based on an assumption that European civilization and Christian religions were superior to Aboriginal culture, which was seen as being savage and brutal". There was also a loss of language and cultural traditions during this time.

Similar histories resonate through the Americas and Oceania. Aboriginal people were forbidden to speak their language and practice cultural traditions [37][38]. Central to the losses endured is the loss of the original languages and the word power they possess. Indigenous languages are linked to histories and cultures that are connected to traditional wisdom about ecology, including traditional medicines that all of us on this vulnerable planet can benefit from. Indigenous languages are disappearing over the world, and with this, 
spirituality is also lost [39]. Losing Indigenous languages affects the knowledge that is needed for good governance, peace, reconciliation, and development in communities [40]. Above all, the loss of language impacts Indigenous people's basic human rights[40]. The Mi'kmaw people of Eastern Canada believe that losing their language, part of their culture, would be harmful [41]. The language of Mi'kmaw is richly expressive, verb-oriented rather than nounoriented as are the Indo-European languages, with whole sentences sometimes consisting fully of verbs. Mi'kmaw is based primarily on a worldview of concepts in terms of communal relationships with one another and the natural environment. The placement of the self in the Mi'kmaw language structure is not centralized; in fact, there is no distinct, separate word for the self, as the self only exists in an already-existing relationship. The word mkamlamun means heart-mind, as the emotive and cognitive cannot be separated conceptually in this language[41]. The Mi'kmaw word netukulimk translates "to develop the skills and sense of responsibility required to become a protector of other species" [6]. Loss of language is linked to loss of identity and culture, which leads to physical, mental, emotional, and spiritual harm [42]. The TRC notes the urgency of the preservation of Aboriginal languages.

\section{Research in indigenous women's health}

Research can help to bring to view attitudes and actions that value people; it can build lasting reconciliatory relationships with communities. Research brings knowledge; which exists across all cultures. Recognizing ways to maintain authentic Aboriginal culture is a way of helping people restore pride in their culture and be at peace within themselves and their communities, as well as advocating for justice, reconciliation, and healing. Despite the many atrocities, Aboriginal cultural traditions and values have been preserved, and serve as a testament to the resiliency of the people [43]. For example, conducting research with Mi'kmaw women and Pap-smear screening [22] found that some women talked openly about Residential School's impact on their health. In some instances, women became angry and tearful. They talked about abuse, neglect, and losses. Some women communicated being physically and psychologically uncomfortable when accessing healthcare due to the pain and abuse that filtered down from Residential Schools and communicated that abuse and loss still exist today in their community. Another participant talked about women being abused sexually and believed that is a reason why probably some of them would not seek healthcare.

However, Indigenous people have not always welcomed white researchers [44][45]. Some researchers have exploited disadvantaged people [45]. For example, in the mid-20 $0^{\text {th }}$ century, there is research showing Canada as depriving children of nutrition without their awareness or consent to study the effects of induced malnutrition in children in Aboriginal communities and Residential Schools[46].

There is an apparent tension between non-Indigenous researchers using an Indigenous methodology and an Indigenous research paradigm [47]. The concern is that "there is a paradigm inherent to Indigenous peoples that cannot simply be adopted from a EuroCanadian or Eurocentric perspective". Aboriginal health researchers use research methodologies that are community-based, participatory, and reflective of Indigenous epistemology[48][49]. Likewise, non-Indigenous researchers need to use Indigenous methodologies and ways of knowing in consultation with the Indigenous research participants and communities.

\section{Aboriginal distrust of non-aboriginal clinicians and researchers}


In Canada, Aboriginal women experience high rates of substandard health care including 'medical colonialism'-medical control over a birth that includes historical patterns of racism and discourses of 'risk' that fail to acknowledge the voices of aboriginal women about root causes of the risks to their health and that of their babies [17]. For example, Inuit women in Canada's northern territories are routinely evacuated, alone, far from their families and communities, to birth in regional hospitals, attended by people they do not know. The evacuation experience contributes to stress and isolation and affects the health of women, children, and families. Seen holistically, physiological birth in the community by a familiar person would usually be safer, though aboriginal midwifery was all but extinguished by colonialized medicine. The political structure and policy itself are culturally disrespectful as relational aspects of birth are devalued within philosophies of care that see every birth as a high-risk medical event.

For example, consider this story, told by one author who had practiced in the Canadian North:

Nukilik [not her real name] was 37 weeks pregnant with her second baby and measured very small for dates; likely intrauterine growth restriction (IUGR). While pressured to fly all women out of the remote hamlet in their last month of pregnancy to give birth, my midwifery colleague and I occasionally attended a healthy birth in the nursing station. The midwifery paradigm holds that normal birth should be kept normal. Nukilik's baby however was small for dates, but she did not want to leave the community. She had no family or friends in the city. She confided that when her partner drank alcohol, he could be abusive. If she left for a few weeks who would protect her firstborn? There was no room for families of birthing mothers in the rented rooms near the city hospital.

With community help, we found a foster home for her child with an auntie, and Nukilik reluctantly agreed to travel. I filled out the referral form to the doctor at the hospital who in turn had access to a neonatologist - which this baby could likely need. There were resources for 24/7 NICU care at the hospital, and flights to tertiary children's hospitals too if needed. I hugged Nukilik as she kissed her firstborn goodbye and boarded the plane. Then the aircraft doors closed, and the plane took off, bound for medical care.

About three days later, my phone rang. "This is Nukilik. I think I am in labor". "Nukilik, where are you?" "Home". "But didn't you go to [the city]?" "Yes, but I did not like it there. I came back on a plane the next day. I am in labor". "Ok, meet me at the nursing station".

Nukilik gave birth about an hour later to a tiny baby who needed more respiratory support. then we could give, and we flew the baby in an incubator with oxygen out to the hospital on the next scheduled flight, but without the mother. Nukilik pumped breastmilk at home, and we froze it for her at the nursing station. A few weeks later, the baby returned home, and we supported this little family, coaxing pumped breastmilk and then breastfeeding. Success!

Later that summer, as I left for my home, Nukilik and her children came to see me off. Standing together, she tells me, "We just get to know one nurse, she flies away, and another nurse comes. Why must you leave so soon?" I was sad to leave and replied, "perhaps it would make sense if there were Inuit nurses, who could stay". Nukilik replied, "I wouldn't want an Inuit nurse, because Inuit wouldn't be as smart as Qallunaat [non-Inuit] nurses.

From the northern sky, I looked down at the vast tundra and reflected on the resiliency and survivorship of the people of this land. How can it be that an Inuit woman would consider Qallunaat nurses smarter than Inuit? What had I, what had we, done wrong? Years later, I still cannot forget her, standing there on the windblown tarmac, looking sad, her baby in her amoutik gazing at me with wide eyes. I also have since read that in Inuit tradition, midwives 
remain part of the mother and baby's spiritual support network for the years that follow the birth.

Before professional nurses provided primary care, Indigenous midwives attended women in childbirth as part of the web of community life [50][51]. Many healthcare providers in the remote north are part of a broader culture in which the accumulation of transient encounters contributed to dismantling Indigenous approaches to supporting birth so much so that the Inuit women had internalized a perspective that non-Indigenous ways were superior. This phenomenon refers to: "For the oppressed, a stranger is always by their side, blocking their chosen destination, saying to them "Not that way". Eventually, the experience of oppression becomes internalized External oppression becomes self-oppression"[52].

\subsection{Culturally safe practices}

Culturally safe practices and caring support need development. Consider this story by nurse researchers [19] conducting a study on gestational diabetes mellitus in a group of Mi'kmaw women in Nova Scotia. The participants were unhappy when their health concerns during pregnancy were not taken seriously[19]. For example, when one participant went to a hospital for confirmation and treatment of a broken ankle during pregnancy, she did not receive appropriate health care. The hospital staff said they are not doing an $\mathrm{x}$-ray and sent her home with no crutches. Many people who feel powerless continue to believe they can not ask for services in hospitals because relationships with doctors and nurses tend to perpetuate colonialism. This often results in Aboriginal people concealing/suppressing their feelings because they do not think they have a right to speak up about their concerns. The participant wanted to receive the care she deserved in a culturally competent and culturally safe manner however this was not the case.

Because of the potential health complications associated with gestational diabetes mellitus, the participants required close prenatal monitoring and/or hospitalization in the event of impending complications[19]. This meant that they had to travel frequently for some of their prenatal care outside their First Nations community for appointments with doctors and nurses specializing in perinatal care. Some Mi'kmaw women worried about arriving at the hospital safely when they were in labor. Similar to earlier research findings [53] findings of lack of access to appropriate healthcare contributed to the Mi'kmaw women's fear of not having healthy birth outcomes.

Research has shown a lack of cultural safety and sensitivity when Aboriginal women are forced to seek information about healthcare from Western sources such as pamphlets and other print materials, which are not always representative or reflective of the women's realities [22]. In some instances, women receive culturally unsafe care because of the devaluing of Aboriginal knowledge, traditions, and cultural ways. Yet, some women communicated positive healthcare experiences and described receiving culturally safe healthcare from providers who explained information adequately. Several participants indicated that brochures and other educational materials that are reflective of Aboriginal women's lives positively influenced Aboriginal women to access Pap screening: "It would seem important for them to attend [screening], and they could relate to those women in the pamphlets" [22].

Lack of cultural safety was evident for Mi'kmaq women receiving Pap smear screening in the few Aboriginal pamphlets or teaching tools available or offered in mainstream healthcare settings. Not a single woman in their study was provided with information about health or health care in her language. When asked whether they ever saw or were given Aboriginal 
educational materials when accessing healthcare services one woman responded by saying, "No. There's nothing in Mi'kmaq", and another stated, "No, I never. No." [22].

Non-Aboriginal health professionals need to understand the nature of privilege and power [54][55]. Non-Aboriginal health professionals need to be aware of the harm they may cause if there is insensitivity to power differentials between participants and themselves [56]. A solid understanding of the concepts of providing culturally safe care is needed when conducting research [57]. "Cultural safety would be used in the knowledge-translation process to frame knowledge and prompt critical reflection on specific areas of knowledge" to help ... "foster equity and social justice" [58]. Cultural safety, a term that first originated in New Zealand addresses disparate power relations and inequitable distribution of resources in society for health [59]. Cultural safety extends beyond an understanding of cultural competence to address the underlying conflicts and tensions to build awareness of the role of power, colonialism, racism, and discrimination in interactions between nurses and patients [60]. Cultural safety refers to appropriate care that is determined by the patient and family [61]. To understand power differences, nurses need to reflect on their practice. Understanding cultural safety and how it should be practiced is the responsibility of healthcare professionals [62]. Cultural safety address issues related to power relations and inequitable distribution of resources as mentioned above [59]. "For research to be transformative for Indigenous people, the paradigm shift must focus on interventions that draw on nahi (fairness) rather than tipi (equal)" [63].

Research is a humbling experience partly because it acknowledges that there is much we do not know, yet we can learn from others [64]. In some Indigenous communities, there are extensive collaborating and networking activities occurring [64][65]. Building networks of people who have strong relationships with communities is needed to help build research capacity so they can conduct their research. Some of these women form talking circles to discuss their experiences. Writing and talking about women's experiences are becoming a major research focus, a way of connecting oral story-telling traditions and scholarly discourse in written form to be widely shared so that many can learn from the stories.

Research "processes are expected to be respectful, to enable people, to heal and to educate" [64]. Establishing relationships with community members is key to successful and continued collaboration in First Nations communities[66][19]. The stories of Aboriginal women are the teachers, researchers are messengers, and the research is a step towards lasting partnerships.

\section{Two-eyed seeing: sharing worldviews}

World cultures are comprised of two forms, individualist and collectivist[67]. The dominant culture in Europe and North America is an individualist. However, most of the world's cultures are collectivist where loyalty to the community may outweigh individual rights[67].

Aboriginal knowledge is consistent with collectivism, holistic and intersubjective knowledge. According to Hatcher et. al, "In the Indigenous worldview knowledge check the knowers or learners are intimately connected, in contrast to their separation in many Western sciences" [6]. Where Western science sees objects, Indigenous sciences teach us to be open to the natural world seeing that our physical beings and minds are interconnected and everything is alive physically and spiritually with humans, a small part of the whole [6]. Two-Eyed Seeing is an approach that we propose when working in partnerships with Indigenous women and families. This approach involves moving away from 'either/or' towards 'both/and' perspectives with flattened hierarchies. The Two-Eyed Seeing approach was presented by 
Albert Marshall, a Mi'kmaw educator, and Elder, and is a metaphor for blending scientific and medical knowledge with the Aboriginal culture [68]. One must avoid positioning oneself totally in the western or Indigenous paradigm, when doing Aboriginal research because it may limit one's understanding of the human experience, rather value both entities for developing knowledge through a Two-Eyed Seeing perspective [68].

As Marshall states "it is not enough to go through life with one perspective, we must embrace all the tools" to have a deeper understanding. This approach involves seeing both the strengths of Indigenous ways of knowing and Western knowledge [33]. When Two-Eyed seeing is integrated into research, it promotes different ways of knowing by enabling researchers and participants to acknowledge different world views [69]. This approach provides a means of seeing different worlds. Ethical spaces are needed to create a dialogue for these discussions to take place [70]. Ethical spaces help to facilitate moving forward with actions to address and improve Aboriginal people's health [69]and provide a forum for respectful understanding.

There are strengths to western science, eastern holism, and Aboriginal worldviews that can be integrated. For example, western science provides approaches to prevention or curing diseases with scientifically derived approaches and is among the many success stories of modern medicine [10]. Eastern cultures have shared knowledge such as acupuncture and Reiki. Aboriginal approaches to healing such as sweat lodges, smudging, and talking circles are important to restoring balance and managing chronic disease and spiritual distress [71][72]. Talking circles are a method of demonstrating respect, active listening, and learning without having debates or arguing about particular issues [73]. Combining various strengths and wisdom and/ or recognizing the benefits of each must be apparent in healthcare setting practices and policies. The western scientific paradigm presents an incomplete perspective on knowledge development. Modern medical practice is rooted in the scientific method premised on biological discovery and elucidation of underlying mechanisms [74]. The logic of this approach is compelling but has resulted in an increasingly reductionist framework. Reductionism is a framework that developed from the teaching of Descartes, who suggested that understand things, one must break them down into parts. The Cartesian view is based on the premise that the mind and body are separate[75]. This 'medical model' is used to approach patients as a collection of visceral organs and a nervous system [75] that separates mind from body, eliminates most references to spiritualism and neglects social, historical, and political causes of illness. This approach continues to dominate western health care, including nursing and is seen in how clinical facilities and research are organized to represent body systems (e.g. cardiology, orthopedics, gynecology), and where 'mental health' is medicalized and treated as an entity unto itself, rather than a component of everything related to health and illness. It is difficult to undo the effects of this scientific worldview to even enter into relationships where patients are equal partners. Moreover, western science, until recently, was patriarchal in orientation and placed itself in a position of privilege over more traditional forms of knowledge. Such systems marginalize other ways of knowing and leave little room for authentic partnerships such as between Aboriginal and non-Aboriginal people.

\subsection{Connecting nursing theory to indigenous ways}

Nursing has claimed a philosophical orientation to holism as early as Florence Nightingale's work. Similarly, Indigenous beliefs are founded on connectedness and holism. We are now challenged to work together in authentic partnership to co-create a shared understanding of holism and how we learn together. About Leininger's work, "Transcultural 
nursing refers to a formal area of humanistic and scientific knowledge and practices focused on holistic culture caring, phenomena, and competencies to assist individuals or groups to maintain or regain their health and well-being"[76].

In Leininger's culture care nursing theory, holistic and comprehensive knowledge in transcultural nursing necessitates understanding emic (traditional, indigenous) and etic (professional) perspectives. Both emic and etic health factors need to be brought together into care practices for health and wellbeing. Leininger's Culture Care Theory [77] includes integrative care practices as essential to transcultural nursing, blending emic and etic approaches. What Leininger calls integrative emic-etic care, Mi'kmaw Elders capture metaphorically through a 'Two-Eyed Seeing' approach.

The growing number of 'holistic practitioners' and professions reclaiming an orientation to holism -including nursing, midwifery, and 'integrative medicine'- suggests a growing societal awareness of the limitations of the medical model. The philosophical bases of nursing are concerned with humanism and seeing people from a holistic perspective[78]. Nurses who practice from a holistic perspective, believe that human beings with a mind, body, and soul are in constant interaction with the universe [79]. Health and well-being are dependent on harmony in relationships. "Healing is the journey toward holism" [79]. By using compassion and acceptance, nurses can facilitate healing and help patients to find meaning in their lives. Holism as a philosophical base for nursing has been articulated by contemporary nurse theorists such as Parse's theory of human becoming [80]. From the human becoming perspective, trust in nurse-patient relationships surfaces as individuals describe lived experiences, while nurses in true presence bear witness to persons' health and quality of life[80].

Another contemporary nurse theorist maintains that the power we have as nurses can be operationalized as 'power over' more vulnerable others or it can be operationalized as a power for peace and understanding [81]. Power over powers includes the powers of results, prescription, division, force, hierarchy, command, opposites, use, accumulation, causality, expediency, xenophobia, secrets, rules, and fear [81]. Powers of peace include the powers of process, letting go, the whole, collectivity, solidarity, sharing, integration, nurturing, distribution, intuition, consciousness, diversity, responsibility, creativity, and trust [81]. Unfortunately, some interactions between western professionals and Indigenous people have too often involved the former forms of power. It is time to consider shifting the paradigm to the powers of peace.

Health professionals from privileged places need to work in a spirit of accompaniment with marginalized people - a movement that has the potential to repair the profound injustices and abuses of power that have denied human rights and caused suffering for many of the world's people. Accompaniment is an everyday term, etymologically derived from the Latin ac-com-panis, meaning 'to break bread together'. "To accompany someone is to go somewhere with him or her... There's an element of mystery, of openness, of trust, in accompaniment"[10]. Accompaniment involves bearing witness to the suffering of others. Trust involves freely choosing options that arise from speech, silence, movement, and stillness [82].

\section{Humanistic health care and research}

Non-Aboriginal nurses can conduct respectful research in collaboration with Aboriginal people [43]. Conducting meaningful research will require having a conversation, and a back and forth discussion between Aboriginal women and families and non-Aboriginal health 
professionals. During the research process, it is important to ask: "How are you?" [83] and genuinely listen. For example, Mi'kmaw mothers described nurses who were present for them as 'angels. Nurses, for instance, have always accompanied people during birth, death, illness, and life transitions. Presence refers to "bearing witness to other people's lives" [84]. Bearing witness through research is a natural extension of the nurse's role. Bearing witness involves the relational values of respect, relevance, reciprocity, and responsibility [9] core attributes that we believe we need to foster and sustain working relationships with Aboriginal women.

\subsection{Respect}

The word respect comes from the Latin respicere meaning 'to look again' (re-spect) (Dillon, 1992) - to rethink a situation or event, to reconsider it, and to see beyond the surface and superficial responses that characterize lack of mindfulness [85]. To ignore, neglect, or disregard something, or to dismiss it lightly, is to not respect it[85]. "Respect for persons as existential selves involves more than detached disregard for abstract autonomy; it entails attentive discernment and valuing of an individual as unique" [86]. Respect refers to recognizing the cultural values and traditions of First Nations peoples [9].

What is respect? Respect involves cherishing something as having great value and as fragile, calling for special care. Care and respect involve strengthening connections among pe people in ways that benefit all of us. Care and respect bring people together in the community who have similar concerns [85]. As such, care respect can be likened to the concepts of ethical space and Two-Eyed Seeing to involve such discovery, repair, and strengthening of connections between Aboriginal people and non-Aboriginal nurses.

For example, the first author [87] described a conversation with one of her participants in a study exploring the experiences of Mi'kmaw women with gestational diabetes mellitus (GDM): One participant spoke my name ever so gently. The first author remembers the genuineness in her voice. Her openness helped me to obtain a fuller understanding of her life. I may have glossed over her words of 'feeling sick' if I had not listened carefully. In the Mi'kmaw culture, the words 'feeling sick' refer to going into labor or menstruating. Many people interpret feeling sick as a transient physical illness. However, the participant's description of feeling sick was much deeper. She had a strong inner connection with her baby, and she knew she was going to give birth soon. Respect is a core value in nursing and is articulated in professional Codes of Ethics[78]. "Respect for persons recognizes the intrinsic value of human beings and the respect and consideration that they are due [88]. Also, "respect is the cornerstone of many Aboriginal philosophies" [89] which transcends and situates relationships [86]. "Respect can be seen to involve a determination to discover, forge, repair, and strengthen connections among persons in ways that benefit all of us, through an appreciation of individuality and interdependence" [85] Respect can be likened to the concept of 'Two-eyed seeing' [68] creating ethical space for research with Aboriginal people [70]. The development of respect within nursing practice and scholarship involving partnerships between non-Aboriginal nurses and Aboriginal people can be informed by an understanding of the concept of cultural safety as it is grounded in respect and acknowledgment of the implications of power relationships, racism, and prejudice in the context of past relationships and possible futures between groups.

\subsection{Relevance}

Relevance serves as another component that needs consideration when conducting research in First Nations communities. Researchers must respect the cultural integrity of Aboriginal 
people and recognize what they value as Indigenous knowledge [9]. Research in the past has not always been relevant to Aboriginal peoples' health needs [90]. For example, issues related to living with diabetes, parenting, and mental health have been identified by Aboriginal people as being relevant and timely health issues, deserving of Aboriginal-focused research [91].

\subsection{Reciprocity}

Reciprocity is a fundamental Aboriginal core value, which occurs through a two-way process of learning and exchanging ideas [9]. It entails honoring each other's roles and a balance of sharing and acquiring knowledge [92]. Reciprocity is accomplished by actively engaging in knowledge development and the sharing of stories in safe spaces that foster mutuality and trusting relationships.

\subsection{Responsibility}

Responsibility refers to helping Aboriginal people empower themselves by inviting them to be active participants in the research process at all of its stages. Researchers have a responsibility to create a welcoming environment to help Aboriginal people feel safe [9] and ensure sacred spaces and traditional knowledge are respected. For example, Mi'kmaw participants participated in a study involving conversations and talking circles about gestational diabetes mellitus [19]. As a result, participants were receptive to participating and became active participants in the study. Components of the medicine wheel as a specific example of a conceptual framework, grounded in Aboriginal traditional knowledge and beliefs, to guide understanding Aboriginal women's experiences of Pap smear screening[93].

\section{Recommendations}

\subsection{Recommendations for research}

Engaging Indigenous women in participatory research studies can provide an educational and meaningful learning experience. This gives women an opportunity to share their thoughts and experiences, demonstrating their voice and resilience. Indigenous participants need to be involved in writing up the research that they participated in. They can be involved in various ways and as they wish.

\subsection{Recommendations for practice}

Institutions and communities could benefit from the contributions of Indigenous Knowledge Keepers whereby healthcare providers can learn the culturally safe practice. Education in the Two-Eyed Seeing approach is needed to help healthcare providers understand historical context impacts healthcare outcomes. The TRC commission calls to action report on policy development, practice, and education for all health care and educational institutions [1].

In recent years, the World Health Organization has denounced the prevalence of disrespectful maternity care and called for a human rights framework to guide maternity care [94]. A rights-based approach to maternity care calls upon care to be based upon care to involve respect for choices and preferences including companionship during care; dignity and respect; freedom from discrimination and equitable care; liberty, autonomy, and freedom from coercion [95]. 


\section{Conclusion}

Non-Aboriginal health researchers can contribute to Aboriginal health if they ascribe to a humanistic and caring nature of health and work from a perspective grounded in respect, relevance, responsibility, and reciprocity. Reciprocity acknowledges the relationship between nurses and Aboriginal people where everyone learns, ideas and beliefs are exchanged with respect, and everyone grows in Two-Eyed Seeing. Engaging in meaningful dialogue can help to equalize power relations, in a culturally safe environment. Health care with Indigenous women requires respectful partnerships as the foundation of culturally safe healthcare.

\section{References}

[1] Truth and Reconciliation Commission of Canada [TRC], "Final report of the truth and reconciliation commission of Canada, volume one: Summary: Honoring the truth," reconciling for the future, Toronto, ON: James Lorimer \& Company, (2015)

[2] Indigenous Services Canada, "Preventing and managing chronic disease in First Nations communities: A guidance framework," Retrieved from http://publications.gc.ca/collections/collection_2018/aanc-inac/H34313-1-2017- eng.pdf, (2018)

[3] R. Dyck, N. Osgood, T.H. Lin, A. Gao, and M.R. Stang, "Epidemiology of diabetes mellitus among first nations and non-first nations adults," Canadian Medical Association Journal, vol.182, no.3, pp.249-256, (2010)

[4] C. Loppie Reading and F. Wein, "Health inequalities and social determinants of Aboriginal people's health," Retrieved from https://www.nccah-ccnsa.ca/docs/social\%20determinates/nccah-loppie-wien_report.pdf, (2009)

[5] C. Loppie, "In determinants of indigenous people's health: Beyond the social," Edited M. Greenwood, S. D, Leeuw, N. M. Lindsay, Toronto, Canadian Scholars, pp 3-17, (2018)

[6] A. Hatcher, C. Bartlett, A. Marshall, and M. Marshall, "Two-eyed seeing in the classroom environment: concepts, approaches, and challenges," Canadian Journal of Science, Mathematics and Technology Education, vol.9, no.3, pp.141-153, (2009)

[7] P. Knudtson and D. Suzuki, "Wisdom of the elders. Toronto," ON: Stoddart

[8] Government of Canada, "Crown decisions relations and Northern Affairs Canada," Retrieved from: https://www.rcaanc-cirnac.gc.ca/eng/1100100013785/1529102490303, (2019)

[9] V.J. Kirkness and R. Barnhardt, "First Nations and higher education: The four's - respect, relevance, reciprocity, and responsibility,” Journal of American Indian Education, vol.30, no.3, pp.1-10

[10] P. Farmer, "To repair the world," Berkeley, CA: the University of California Press, (2013)

[11] World Health Organization [WHO], "WHO recommendation on respectful maternity care during labor and childbirth," Retrieved from https://extranet.who.int/rhl/topics/preconception-pregnancy-childbirth-andpostpartum-care/care-during-childbirth/who-recommendation-respectful-maternity-care-during-labour-andchildbirth, (2018)

[12] F. Kolahdooz, K. Launier, F. Nader, K.J., Yi, P. Baker, T.L. McHugh, H. Vallianatos, and S. Sharma, "Canadian Indigenous women's perspectives of maternal health and health care services: A systematic review," Diversity and Equality in Health Care Services, vol.13, no.5, pp.334-348, (2016)

[13] M.A. Bohren, J.P., Vogel, J.P., E.C. Hunter, O. Lutsiv, S.K. Makh, J.P. Sousa, C. Aguiar, F.S., F.S Coneglian, A. Luiz, A. Diniz, O. Tuncalp, D. Javadi, O.T. Oladapo, R. Khosla, M.J. Hindin, and A.M. Gulmezoglu, "The mistreatment of women during childbirth in health facilities globally: A mixed-methods systematic review," PLoS Medicine, vol.12, no.6, e1001847, (2015)

[14] F. Diaz-Tello, "Invisible wounds: Obstetric violence in the United States," Reproductive Health Matters, vol.24, no.47, pp.56-64, (2015) DOI: 10.1016/j.rhm.2016.04.004 
Health Care with Indigenous Women: Respectful Partnerships

[15] S. Hennig, "Shut up... and push! - Obstetrical violence, dignified health care, and the intersection with Human Rights," Retrieved from http://jis.athabascau.ca/index.php/jis/article/view/216/328, (2016)

[16] H. Goer, "Cruelty in maternity wards: Fifty years later," Journal of Perinatal Education, vol.19, no.3, pp.3342, (2010) DOI:10.1624?105812410X514413

[17] A. Brown, C. Varcoe, and B. Calam, "The birthing experiences of rural aboriginal women in context: Implications for Nursing," Canadian Journal of Nursing Research, vol.43, no.4, pp.101-117, (2011)

[18] J. Whitty-Rogers, J., Etowa, and J., Evans, "Until Our hearts are on the ground: Aboriginal mothering, oppression, resistance and rebirth community in Nova Scotia,” Edited D.M. Lavel-Havard \& J.C. Lavel (Ed.), Toronto, On Demeter Press, (2006)

[19] J. Whitty-Rogers, V. Caine, and B. Cameron, "Aboriginal women's experiences with gestational diabetes mellitus: A participatory study,” Advances in Nursing Science, vol.39, no.2, pp.181-198, (2016).

[20] R. Reed, R., Sharman, C. Inglis, "Women's description of childbirth trauma relating to care provider actions and interactions," BMC Pregnancy and Childbirth, vol.17, no.1, pp.21, (2017)

[21] M. Sadler, M.J. Santos, D. Ruiz-Berdún, G.L. Rojas, E. Skoko, P. Gillen, and J.A. Clausen, "Moving beyond disrespect and abuse: addressing the structural dimensions of obstetric violence," Reproductive Health Matters, vol.2, no.47, pp.47-55, (2016)

[22] C. MacDonald, R. Martin-Misener, A. Steenbeek, and A. Browne, "Honoring stories: Mi'kmaq women experiences with pap smear screening in eastern Canada," Canadian Journal of Nursing Research, vol.47, no.1, pp.72-96, (2015)

[23] A. J. Browne and A. J., "The meaning of respect: A First Nations perspective," Canadian Journal of Nursing Research, vol.27, no.4, pp.95-109, (1995)

[24] A.J. Browne and J. Fiske, "First nations women's encounters with mainstream healthcare services," Western Journal of Nursing Services, vol.23, no.2, pp.126-147, (2001)

[25] A.J. Browne, "Clinical encounters between nurses and First Nations women in a western Canadian hospital," Social Science \& Medicine, vol.64, pp.2165-2176, (2007)

[26] D. Gregory, D., and J. Harrowing, "Indigenous people's health and health-care equity: Seven years later," Canadian Journal of Nursing Research, vol.44, no.2, pp.15-18, (2012)

[27] Canadian Nurses Association, "Code of ethics for registered nurses," Retrieved from https://www.cnaaiic.ca/ /media/cna/page-content/pdf-en/code-of-ethics-2017-edition- secure- interactive, (2017)

[28] The National Aboriginal Council of Midwives, "What is an indigenous midwife?" Retrieved from https://indigenousmidwifery.ca/indigenous-midwifery-in-canada

[29] A.J. Browne, C. Varcoe, J. Lavoie, V. Smye, S.T. Wong, M. Krause, D. Tu, O. Goodwin, K. Khan, and A. Fridkin, "Enhancing health care equity with Indigenous populations: Evidenced-based strategies from an ethnographic study," BioMed Central, vol.16, article no.544, (2016) DOI 10.1186/s12913-016-1707-9

[30] A.J. Browne, "Discourses influencing nurses' perceptions of first nations patients," Canadian Journal Nursing Research, vol.37, no.4, pp.62-87, (2005)

[31] M.D. Stout, "Ascribed health and wellness, Atikowisi miýw__ay_awin, to achieved health and wellness, Kaskitamasowin miýw-a_ay_awin: Shifting the paradigm,” Canadian Journal of Nursing Research, vol.44, no.2, pp.11-14, (2012)

[32] S. Flicker and C.A. Worthington, "Public health research involving Aboriginal peoples: Research ethics board stakeholders' reflections on ethics principles and research process," Canadian Public Health Association, vol.101, no.1, pp.19-22, (2012)

[33] M. Iwama, M. Marshall, M. A. Marshall, and C. Bartlett, "Two-eyed seeing and the language of healing in community-based research," Canadian Journal of Native Education, vol.32, no.2. pp.3-23, (2009)

[34] W. Warry, "Ending denial: Understanding Aboriginal issues," Peterborough, ON: Broadview Press, (2007)

[35] R.T. Pastore, “The Beothuk," Retrieved from http://www.heritage.nf.ca/aboriginal/beothuk.html, (1997)

[36] Aboriginal Healing Foundation, "Dancing, stinging, and speaking the healing story: Healing through creative arts,” http://www.ahf.ca/downloads/healing-through- creative-arts.pdf, (2012) 
[37] Canadian Institute of Health Research, "CIHR guidelines for health research involving Aboriginal people," Ottawa, On: Author, (2007)

[38] L. Knockwood, "Out of the depths: The experiences of Mi'kmaw children at the Indian residential school at Shubenacadie,” Blackpoint, NS, Canada: Fernwood Publishing, (2001)

[39] M. King, A. Smith, and M. Gracey, "Indigenous health part 2: The underlying causes of the health gap," Lancet, vol.3, No.74, pp.76-84, (2009)

[40] United Nations Department of Economic and Social Affairs, 2019 International year of Indigenous languages. Retrieve from https://www.un.org/development/desa/dspd/2019/01/2019-international-year-of- indigenouslanguages, (2019)

[41] T. Sable. and B. Francis, "The language of this land, Mi'kma'ki," Sydney, NS: Cape Breton University Press, (2012)

[42] O. McIvor, A. Napoleon, and K.M. Dickie, "Language and culture as protective factors for at-risk communities,” Journal of Aboriginal Health, pp.6-25, (2009)

[43] L.J. Kirmayer, S. Dandeneau, E. Marshall, M.K. Phillips, and K. Williamson, "Rethinking resilience from indigenous perspectives," The Canadian Journal of Psychiatry, vol.56, no.2, pp.84-91, (2011)

[44] V. Deloria, "Custer died for your sins," New York: The Macmillan Co.

[45] E.J. Hedicare. Editor, "Applied anthropology in Canada: understanding Aboriginal issues,” $2^{\text {nd }}$ Ed, Toronto: the University of Toronto Press, (2008)

[46] I. Mosby, "Administering colonial science: Nutrition research and human biomedical experimentation in Aboriginal communities and residential schools, 1942-1952," Histoire Sociale/Social History, vol.46, no.91, pp.145-172, (2013) DOI:10.1353éhis.2013.0015

[47] M. Battiste, "Decolonizing education: Nourishing the learning spirit," Vancouver, BC: UBC Press, (2013)

[48] C. Bourassa, J. McElhaney, and E. Olesen, "Cultural safety," Retrieved from https://www.queensu.ca/sps/sites/webpublish.queensu.ca.spswww/files/files/Events/Conferences/RCAP/Papers/Bourassa_RCAP_concept sOct2016.pdf, (2016)

[49] D. Martin, "Two-Eyed Seeing: A framework for understanding Indigenous and non-Indigenous approaches to Indigenous health research," Canadian Journal of Research, vol.42, no.2, pp.20-42, (2012)

[50] B. O'Brien, "Birth on the land: Memories of Inuit elders and traditional midwives," Iqaluit, NU: Nunavut Arctic College, (2012)

[51] J.S. Savage, "Postmodern implications of modern childbirth," International Journal of Childbirth Education, vol.17, no.4. pp.8-10, (2002)

[52] M. Battiste, "Introduction: Unfolding the lesions of Colonization, in Reclaiming indigenous voice and vision," Editor M. Battiste, pp.xvi-xxx, Vancouver: University of British Columbia Press, (2000)

[53] K. A. Van Herk, D. Smith, and D. A. Andrew, "Identity matter: Aboriginal mother's experiences of accessing health care," Contemporary Nurse, vol.37, no.1, pp.57-68, (2011)

[54] M. McDermott and F.L. Samson, "White racial and ethnic identity in the United States," Annual Review of Sociology, vol.31, pp.245-261, (2005).

[55] E. A. McGibbon and J.B. Etowa, “Anti-racist healthcare practice,” Toronto, ON, Canada: Canadian Scholars' Press, (2009)

[56] A.J. Browne, C.M. Varcoe, S.T. Wong, S. T., V.L. Smye, J. Lavoie, D. Littlejohn, and S. Lennox, "Closing the health equity gap: Evidence-based strategies for primary health care organizations," International Journal for Equity in Health, vol.11, no.59, pp.1-15, (2012)

[57] Aboriginal Nurses Association of Canada (ANAC), "Framework for cultural competence and safety in Aboriginal health nursing living in dignity and truth," Ottawa, ON, (2007)

[58] A.J. Browne, C. Varcoe, V. Smye, S. Reimer-Kirkham, M.J. Lynam, and S. Wong, "Culturally safety and the challenges of translating critically oriented knowledge in practice," Nursing Philosophy, vol.10, pp.167-179, (2009) 
Health Care with Indigenous Women: Respectful Partnerships

[59] I. M. Ramsden, "Cultural safety and nursing education in Aotearoa and Te Waipounamu," Unpublished master's thesis, Victoria University of Wellington, New Zealand, (2002)

[60] D. Arieli, M. Mashiach, M.J. Hirschfeld, and V. Friedman, "Cultural safety and nursing education in divided societies," Nursing Education Perspectives, vol.33, no.6, pp.364-368, (2012)

[61] D. Doutrich, K., Arcus, L. Dekker, J. Spuck, and C. Pollock-Robinson, "Cultural safety in New Zealand and the United States: looking at a way forward together," Journal of Transcultural Nursing, vol.23, no.2, pp.143150, (2012)

[62] B. J. Astle and S. Barton, "Culture and ethnicity in Canadian fundamentals of nursing (4th ed.)," Editor P. Potter, A. Perry A., K. C. Ross-Kerr., \& M. Wood (Eds.), Toronto, ON, Canada: Mosby, pp.114-131, (2010)

[63] A.J. Browne and M.D. Stout, "Moving towards Nahi: Addressing health equity in research involving indigenous people," CJNR, vol.44, no.2, pp.7-10, (2012)

[64] L.T. Smith, "Decolonizing methodologies: Research and Indigenous peoples," New York: University of Otago Press, (1999)

[65] L.T. Smith, "Decolonizing methodologies: Research and Indigenous peoples (2 ${ }^{\text {nd }}$ Ed.)," New York: Zed Books, (2012)

[66] C. Loppie, "Learning from the grandmothers: Incorporating Indigenous principles into qualitative research," Qualitative Health Research, vol.17, no.2, pp.276-284, (2007)

[67] T. Harding, "Cultural safety: A vital element for nursing ethics," Nursing Praxis in New Zealand, vol.27, no.1, pp.4-11, (2013)

[68] A. Marshall, "Two-eyed seeing: Science education for children and youth," Retrieved from http://www.turtleisland.org/culture/twoeyed.htm, (2007)

[69] A. Vukic, D. Gregory, and R. Martin-Misener, "Indigenous health research: Theoretical and methodological perspectives," Canadian Journal of Nursing Research, vol.44, no.2, pp.146-161, (2012)

[70] W. Ermine, “The ethical space of engagement," Indigenous Law Journal, vol.6, no.1, pp.193-203, (2007)

[71] Canadian Health Network, "Aboriginals peoples glossary," Retrieved from http://www.canadian-healthnetwork.ca/faq faq/aboriginal_peoples-autochtones/glossarye.html, (2000)

[72] M. Johnson, "The presence of Mother Earth in women's ceremonies: Observations of a woman/Wiccan practitioner," Canadian Woman Studies, vol.17, no.1, p.121, (1997)

[73] M.K. Kholghi, G. Bartlett, M. Phillips, J. Salsberg, A.M. McComber, and A.C. Macaulay, "Evaluating an Indigenous health curriculum for diabetes prevention: Engaging the community through talking circles and knowledge translation of results," Family Practice, vol.35, no.1, pp.80-87, (2017)

[74] H.J. Federoff, J.D. Gostin, "Evolving from reductionism to holism: Is there a role for systems medicine?" Journal of the American Medical Association, vol.302, no.9, pp.994-996, (2009)

[75] E.C. Polifroni and M.L. Welch., "In perspectives on philosophy of science in nursing: A historical and contemporary anthology," Edited E.C. Polifroni \& M. L. Welch (Eds.), Philadelphia, PA: Lippincott Williams \& Wilkins, pp.1-11, (1999)

[76] M. McFarland, "Nursing theorists and their work," Edited A.M. Tomey \& M.R. Alligood (Eds.), St. Louis Missouri: Mosby, Elsevier, pp.472-496, (2005)

[77] M.R. McFarland, "In Leininger's Transcultural Nursing: Concepts, theories, research, and practice," M.R. McFarland \& H.B. Wehbe-Alamah (Eds), New York: McGraw-Hill, pp.39-56, (2018)

[78] S. Roach, "Caring, the human mode of being: A blueprint for the health professions," Ottawa, ON: CHA Press, (2002)

[79] H.L. Erikson, "Philosophy and theory of holism," Nursing Clinics of North America, vol.42, no.2, pp.139163, (2007)

[80] R. R. Parse, "Witnessing as true presence," Illuminations, vol.8, no.3, pp.1

[81] P.L Chinn, "Peace and power: Active leadership for building community," Boston, MA: Jones \& Bartlett, (2008) 
[82] T.J. Doucet, "Trusting another: A parse research method study," Nursing Science Quarterly, vol.22, no.3, pp.259-266, (2009)

[83] B.L. Cameron, “The nursing "How are you”?” Phenomenology + Pedagogy, vol.10, pp.172-185

[84] R. Naef, "Bearing witness: A moral way of engaging in the nurse-person relationship," Nursing Philosophy, vol.7, no.3, pp.146-156, (2006)

[85] R.S. Dillon, "Respect and care: Toward moral integration," Canadian Journal of Philosophy, vol.22, no.1, pp.105-132

[86] S. Gadow, "Relational narrative: The postmodern turn in nursing ethics," Scholarly Inquiry for Nursing Practice: An International Journal, vol.13, no.1, pp.57-70, (1999)

[87] J. Whitty-Rogers, “Exploring Mi'kmaq women's experiences with gestational diabetes mellitus," Doctoral Dissertation, University of Alberta, Edmonton, Alberta, (2013)

[88] Canadian Institutes of Health Research, Natural Sciences and Engineering Research Council of Canada, \& Social Sciences and Humanities Research Council of Canada, Tri-Council Policy Statement: Ethical Conduct for Research Involving Humans. Ottawa, ON: Government of Canada, (2014)

[89] J. Smylie, K. Bailey, E.L. Eason, Q, C. R. Grey, A. Archambault, M.M. Cummings, P. Lessard, C. Cuchie, W.J. Goldsmith, K.Seethram, H. Cohen, and Q.C. B.Downey, "SOGC policy statement: a guide for health professionals working with aboriginal peoples," The sociocultural context of Aboriginal peoples in Canada, vol.22, no.12, pp.1070-1081, (2000)

[90] T.K. Young, "Review of research on Aboriginal populations in Canada: Relevance to their health needs," British Medical Journal, vol.327, pp.419-422, (2003)

[91] S. Barton, "Discovering the literature on Aboriginal diabetes in Canada: A focus on holistic methodologies," Canadian Journal of Nursing Research, vol.40, no.4, pp.26-54, (2008)

[92] M. Pidgeon and D.G. Hardy Cox, "Researching with Aboriginal peoples: Practices and principles," Canadian, Journal of Native Education, vol.26, no.2, pp.96-106, (2002)

[93] C. MacDonald, "Using components of the medicine wheel for the development of a conceptual framework for understanding Aboriginal women in the context of Pap smear screening," Pimatisiwin Journal: A Journal of Aboriginal and Indigenous Community Health, vol.6, no.3, pp.95-108, (2008)

[94] World Health Organization [WHO], "The prevention and elimination of disrespect and abuse during facilitybased childbirth,” Retrieved from https://apps.who.int/iris/bitstream/handle/10665/134588/WHO_RHR_14.23_eng.pdf, (2015)

[95] White Ribbon Alliance [WRA], "Respectful maternity care: The universal rights of childbearing women," Retrieved from https://www.whiteribbonalliance.org/wpcontent/uploads/2017/11/Final_RMC_Charter.pdf, (2011) 


\section{Authors}

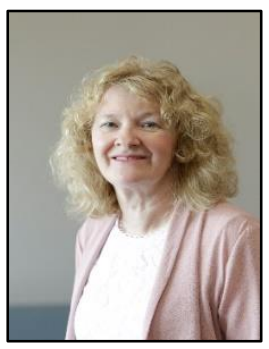

\section{Dr. Joanne Whitty-Rogers}

She is a Senior Research Professor at St Francis Xavier University Rankin School of Nursing, formerly an Associate Professor. Her various roles included Interim Director, Chair, Accreditation Lead in the School, and co-led the introduction of a new BScN curriculum and LPN-BScN Pathway. She taught courses in professional nursing, health promotion, perinatal nursing, research methods, and trends in health care. Her research is in Indigenous women's health with a focus on gestational diabetes mellitus and diabetes, social determinants of health, Indigenous student mentorship, and the quality of care in stroke and myocardial infarct patients in Nova Scotia.

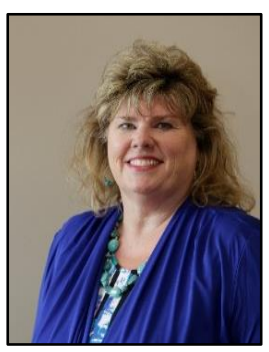

\section{Dr. Cathy MacDonald}

She is Associate Dean and Associate Professor at St Francis Xavier University Rankin School of Nursing. Her research focuses on cancer and marginalized individuals, Aboriginal women and Pap smear screening, participatory action research, and Indigenous health. She has also been a co-applicant and co-investigator (Canadian Institute Health Research, Health Canada, Canadian Immunization Research Network, Atlantic Policy Congress of First Nations Chiefs Secretariat) on several national research grants. She has published in a number of national and international peer review journals. Cathy has presented her research work at conferences locally, nationally, and internationally.

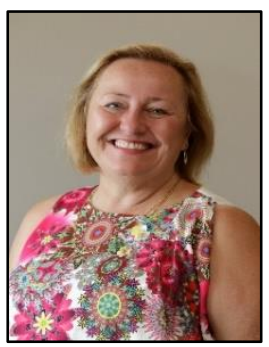

\section{Marion Alex}

She is a faculty member at the Rankin School of Nursing in Antigonish, NS, Canada with a background in maternal/child health and nursing education. 